Article

\title{
Rhizomucor miehei Lipase Supported on Inorganic Solids, as Biocatalyst for the Synthesis of Biofuels: Improving the Experimental Conditions by Response Surface Methodology
}

\author{
Juan Calero ${ }^{1}$, Diego Luna ${ }^{1, *}$, Carlos Luna ${ }^{1}$ D , Felipa M. Bautista ${ }^{1}$, Beatriz Hurtado ${ }^{1}$, \\ Antonio A. Romero ${ }^{1}$ (D), Alejandro Posadillo ${ }^{2}$ and Rafael Estevez ${ }^{1}$ \\ 1 Departamento de Química Orgánica/Universidad de Córdoba, Campus de Rabanales, Ed. Marie Curie, \\ 14014 Córdoba, Spain; p72camaj@gmail.com (J.C.); qo2luduc@uco.es (C.L.); qo1baruf@uco.es (F.M.B.); \\ b.hurtadocebrian@gmail.com (B.H.); qo1rorea@uco.es (A.A.R.); rafa_20_15@hotmail.com (R.E.) \\ 2 Seneca Green Catalyst S.L., Campus de Rabanales, 14014 Córdoba, Spain; seneca@uco.es \\ * Correspondence: diego.luna@uco.es; Tel.: +34-957212065
}

Received: 12 February 2019; Accepted: 26 February 2019; Published: 2 March 2019

\begin{abstract}
Two inorganic solids have been evaluated as supports of Lipozyme RM IM, a Rhizomucor miehei lipase immobilized on a macroporous anion exchange resin, in order to improve its application as a biocatalyst in the synthesis of biofuels. The experimental conditions have been optimized to get the selective transesterification of sunflower oil, by using a multi-factorial design based on the response surface methodology (RSM). In this way, the effects of several reaction parameters on the selective ethanolysis of triglycerides to produce Ecodiesel, a biodiesel-like biofuel constitute by one mole of monoglyceride (MG) and two moles of fatty acid ethyl ester (FAEE), have been evaluated. Thus, it was obtained that a 6:1 oil/ethanol molar ratio, $0.215 \mathrm{~g}$ of biocatalyst supported in silica-gel ( $0.015 \mathrm{~g}$ Lipase $/ 0.2 \mathrm{~g}$ silica-gel), $50 \mu \mathrm{L}$ of $10 \mathrm{~N} \mathrm{NaOH}$, together with previous optimized reaction parameters, $35^{\circ} \mathrm{C}$ reaction temperature and $120 \mathrm{~min}$ of reaction time, gave the best results (conversions around 70\%; selectivity around $65 \%$; kinematic viscosities about $9.3 \mathrm{~mm}^{2} / \mathrm{s}$ ) in the reaction studied. Besides, Lipozyme RM IM, supported on silica-gel, biocatalyst exhibited a very good stability, remaining its activity even after 15 cycles.
\end{abstract}

Keywords: biodiesel; Ecodiesel; selective ethanolysis; sunflower oil; Lipozyme RM IM; Rhizomucor miehei; ANOVA method; response surface methodology

\section{Introduction}

The transport sector is currently facing an unprecedented challenge. On the one hand, fossil fuels represent more than $95 \%$ of the energy employed in this sector, increasing day by day. However, as fossil fuels have a finite nature, they cannot cope with this demand indefinitely. On the other hand, the control of greenhouse gas emissions, including $\mathrm{CO}_{2}$, is mandatory for environmental purposes. Thus, an smooth transition from the current scenario, in which diesel engines work mainly with fossil fuels, to another in which these engines will work mainly with renewable biofuels would allow to respond the increasing demand on fuels, as well as to partially solve the environmental issues [1,2].

In fact, biofuels have been postulated as the best option to replace fossil fuels, since to date, electric motors or vehicles capable of using fuel cells cannot compete yet with explosion or combustion engines, especially in the field of heavy trucks [3], aviation [4,5], or the shipping sector [6]. Therefore, research on renewable fuels capable of replacing fossil fuels and allowing current engines to operate without any modification constitutes a first order priority $[7,8]$. Among biofuels, biodiesel is considered the 
best option to replace fossil fuels in compression ignition diesel engines, since no modifications have to be performed [8-11]. Industrial production of biodiesel is currently carried out by homogeneous alkali-catalyzed transesterification of vegetable oils with methanol [12]. After the reaction, biodiesel is repeatedly washed with water to remove glycerol and soaps [13]. In this process, the generation of glycerol as byproduct is a major issue for both, the high amount of glycerol generated ( $10 \%$ by weight of the total biodiesel produced) and the high amount of water employed for removing it [14]. Thus, to solve this drawback, several alternative methods are being investigated.

One option is the production of glycerol derivatives, with rheological properties like methyl esters of fatty acids, during the same transesterification process. This process allows its dissolution in the biofuel and/or in the fossil diesel, increasing the yield of the process and also avoiding the separation of glycerol $[15,16]$. To do that, methanol is replaced by other donor agents, such as ethyl (or methyl) acetate or dimethyl carbonate. Different catalysts have been investigated, including several lipases $[17,18]$. As a result of these transesterification reactions, a mixture of three molecules of FAME or FAEE (fatty acid ethyl ester) and one of glycerol carbonate or glycerol triacetate (triacetin) are obtained $[19,20]$.

Other valuable option is the production of a biofuel, with similar physicochemical properties as biodiesel, which integrates glycerol in the form of monoglyceride. In this field, our Research Group has an extensive background, specifically in the production of Ecodiesel, a biofuel obtained by a selective 1,3-regiospecific enzymatic transesterification of the triglycerides (Scheme 1), so that a mixture of two parts of FAEE and one part of MG is obtained [21]. The experimental conditions of the enzymatic process to produce Ecodiesel are much milder than those required for a conventional homogenous process. In addition, the atomic efficiency of the process is very high, since the yield of the process is practically $100 \%$, avoiding, then, any process to eliminate impurities from the biofuel obtained. Last but not least, as a reagent, ethanol is used, a cheaper compound than dimethyl carbonate or ethyl acetate, both described as alternatives for obtaining biofuels that integrate glycerin as soluble compounds in the biofuel.

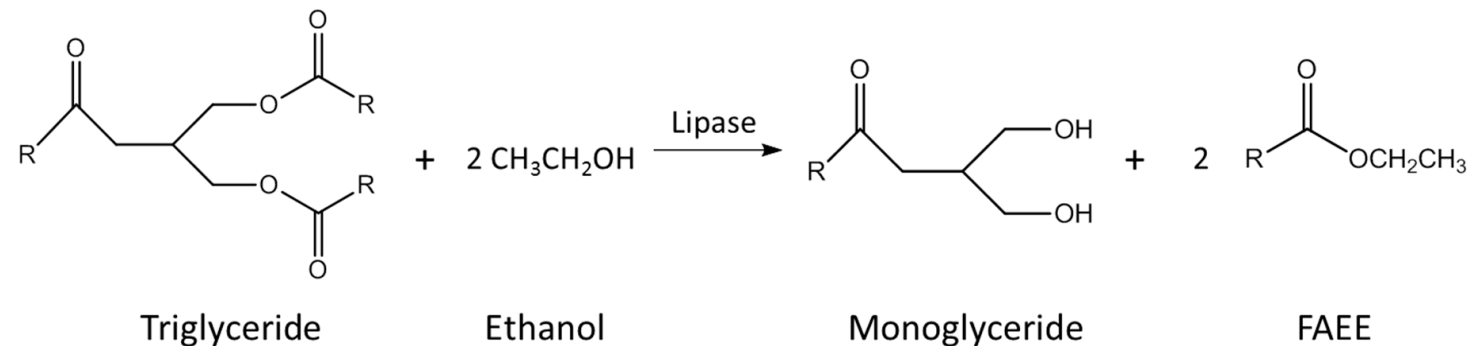

Scheme 1. Ecodiesel synthesis by 1,3-selective ethanolysis of triglycerides, which integrates the glycerol as monoglyceride.

The Ecodiesel synthesis was patented using a pig pancreatic lipase PPL [22], although remarkable results have been also obtained over different microbial lipases [23,24]. To optimize the different reaction conditions, such as the effect of temperature, the $\mathrm{pH}$, the oil/alcohol molar ratio, etc. statistical analysis of variance (ANOVA) and response surface methodology (RSM) have been previously employed in Ecodiesel production [25].

Anyhow, despite lipases can be employed as catalyst to perform the Ecodiesel synthesis, their high production cost is still a huge limitation for their use at industrial scale. To overcome this, lipases must be able to be reused in subsequent reactions, being a viable option its immobilization on a support. In this sense, we have recently reported the immobilization of Lipozyme RM IM, a Rhizomucor miehei lipase, on a macroporous anion exchange resin and its use as heterogeneous biocatalyst in the selective transesterification of sunflower oil with ethanol [26]. Despite the good results obtained, the low density of the polymer resin lipase makes its recovery very difficult, needing a centrifugation operation at $3500 \mathrm{rpm}$ for 5 minutes. Furthermore, a maximum of six reuses can be attained before the loss of the 
activity. From an economical point of view, six reuses are not enough if we take under consideration the high price of the lipase.

Hence, in this research, two different aspects have been addressed. On one hand, to avoid the centrifugation process for recovering the biocatalyst, several immobilization methods on inorganic supports have been evaluated. For that purpose, two different cheap inorganic materials, sepiolite and silica, have been evaluated as supports using covalent immobilization and/or physical adsorption.

On the other hand, several reaction parameters have been studied by ANOVA and RSM, to have better insights into the production of Ecodiesel over the Rhizomucor miehei lipase. We consider this statistical method very helpful because, as we previously observed employing other enzymes, during the production of Ecodiesel, the properties of the enzymes change depending on these reaction parameters, influencing the measured reaction rates [21,25,27]. In this study, we have evaluated the influence of the amount of lipase, the amount of $10 \mathrm{~N} \mathrm{NaOH}$ and the oil/ethanol molar ratio in the production of Ecodiesel.

\section{Materials and Methods}

\subsection{Materials}

Sunflower oil for food use was obtained from a local market. Its standard fatty acids profile is: $63.5 \%$ linoleic acid, $24 \%$ oleic acid, $6.5 \%$ palmitic acid, $5 \%$ stearic acid and $2 \%$ of palmitoleic, with minor amounts of linolenic, behenic, and cetoleic acids. It exhibits a kinematic viscosity value of $32 \mathrm{~mm}^{2} / \mathrm{s}$. The water content as determined by the Karl Fisher method was $<0.08 \%$ and acidity degree $0.2 \%$, expressed as oleic acid content. The palmitic acid, stearic acid, oleic acid, linoleic acid and linolenic acid methyl esters used as standards were obtained from AccuStandard, Inc. 125 Market Street, New Haven, CT 06513, USA and methyl heptadecanoate was purchase from Sigma-Aldrich, San Luis, Misuri, Estados Unidos. All of them were chromatographically pure. Absolute ethanol and sodium hydroxide pure analytical compounds (99\%) used were purchased from Panreac, Carrer del Garraf, 2, 08211 Castellar del Vallès, Barcelona, Spain. The Lipozyme RM IM, a Rhizomucor miehei lipase immobilized in beads from macroporous anion exchange resins was kindly provided by Novozymes A/S, Krogshøjvej 36, 2880 Bagsværd, Denmark.

\subsection{Immobilization of Rhizomucor Miehei Lipase on Inorganic Supports}

\subsubsection{Immobilization of Lipozyme RM IM by Physical Adsorption}

The physical adsorption of Lipozyme RM IM has been studied on two different inorganic supports, a natural sepiolite (Tolsa S.A., Zaragoza, Spain) and a commercial silica gel. The sepiolite is a cheap natural silicate with high surface area $\left(226 \mathrm{~m}^{2} / \mathrm{g}\right)$ and a fibrous structure. The theoretical formula of the unit cell is $\mathrm{Si}_{12} \mathrm{O}_{30} \mathrm{Mg}_{8}(\mathrm{OH})_{6}\left(\mathrm{H}_{2} \mathrm{O}\right)_{4} \cdot 8 \mathrm{H}_{2} \mathrm{O}$, where the $\mathrm{Si}^{4+}$ and the $\mathrm{Mg}^{2+}$ can be partially substituted by $\mathrm{Al}^{3+}, \mathrm{Fe}^{2+}$ and alkaline ions. Each $\mathrm{Mg}$ atom completes its coordination with two molecules of water (Figure 1). The physical adsorption of lipases on sepiolite requires a previous acid demineralization step, in which the different metal hydroxides, i.e., $\mathrm{Al}$, $\mathrm{Fe}$, alkaline ions and mostly $\mathrm{Mg}$, are extracted [28]. In this case, $40 \mathrm{~g}$ of the sepiolite was stirred at RT with a $1 \mathrm{M}$ solution of hydrochloric acid $(\mathrm{HCl})$, until no presence of magnesium is detected $(24 \mathrm{~h})$.

Afterwards, the channels of the sepiolite can be filled with the lipase, producing its immobilization by physical adsorption. For its part, the immobilization on a silica gel does not require any activation treatment of the silica. Thus, the physical immobilization was carried out according to the following procedure. In a $25 \mathrm{~mL}$ round bottom flask, $0.2 \mathrm{~g}$ support, $0.01 \mathrm{~g}$ of Lipozyme RM IM lipase and $3.5 \mathrm{~mL}$ of absolute ethanol are mixed and stirred for $30 \mathrm{~min}$ at $700 \mathrm{rpm}$ and $35^{\circ} \mathrm{C}$. As a matter of density of the solids, the corresponding amount of demineralized sepiolite employed as inorganic support was $1.0 \mathrm{~g}$. The biocatalysts obtained by immobilization will be denoted as Lipo-Sep and Lipo-silica, either if Lipozyme was adsorbed on demineralized sepiolite or on silica-gel. 

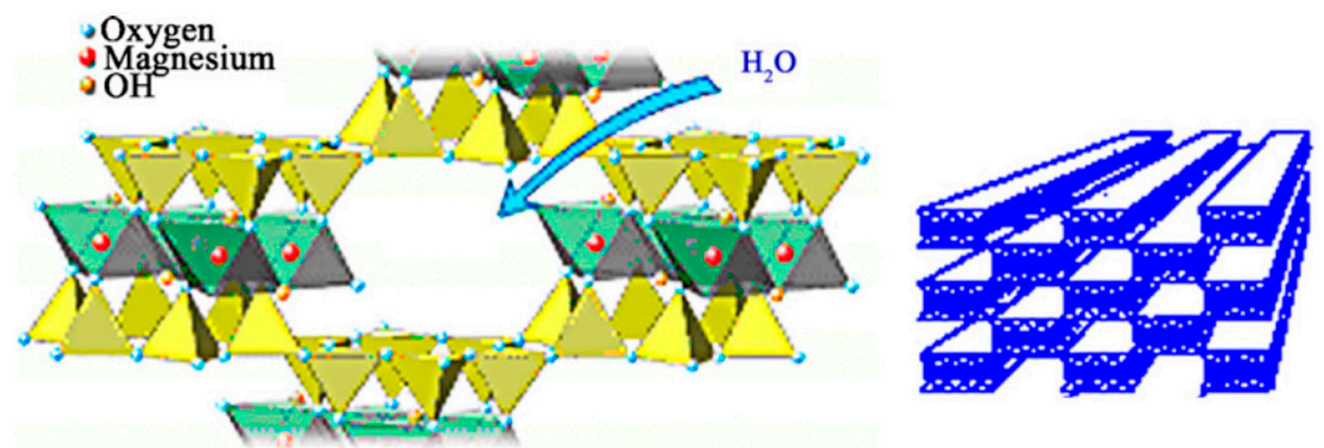

Figure 1. Structure of hydrated natural sepiolite.

\subsubsection{Covalent Immobilization of Lipozyme RM IM on Sepiolite}

Analogously to the physical adsorption, sepiolite cannot be directly employed as support for covalent immobilization of lipases. First of all, it has to be subjected to a surface activation process by sol-gel precipitation of $\mathrm{AlPO}_{4}$ on powdered solid sepiolite, in a proportion Sepiolite/ $\mathrm{AlPO}_{4}$ 80/20 [24]. Then, two different linkers, $p$-hydroxybenzaldehyde or 4-aminobenzylamine, were employed to interact with the Bronsted acid sites of the support, following a reported procedure [28], as it is shown in Schemes 2a and 3a,b. If 4-aminobenzylamine is employed to modify the functional groups in the surface, tereftaldicarboxaldehyde is also added to react with 4-aminobenzylamine and form the imines bond. Briefly, the immobilization of Lipozyme was carried out at room temperature, by introducing the functionalized inorganic solid $(0.2 \mathrm{~g})$ with the Lipozyme RM IM $(0.01 \mathrm{~g})$ in a reaction flask with $6 \mathrm{~mL}$ of ethanol, stirring in a refrigerator for $24 \mathrm{~h}$. Finally, prior to its use, ethanol $(6 \mathrm{~mL})$ was added to the mixture and the solid, with the immobilized Lipozyme was separated by centrifugation. These supports will be denoted as 1-Sep $/ \mathrm{AlPO}_{4}$ for the support modified with $p$-hydroxybenzaldehyde and 2-Sep $/ \mathrm{AlPO}_{4}$ for the support modified with 4-aminobenzylamine and tereftaldicarboxaldehyde. Finally, the covalent immobilization of the lipase on the modified amorphous Sepiolite/ $\mathrm{AlPO}_{4}$ can be achieved by chemical interaction of the organic groups available in the lipase either with the amino group or the aldehyde group, Schemes $2 \mathrm{~b}$ and $3 \mathrm{c}$. The final biocatalysts will be denoted as Lipo-1Sep $/ \mathrm{AlPO}_{4}$ and Lipo-2Sep/ $\mathrm{AlPO}_{4}$.

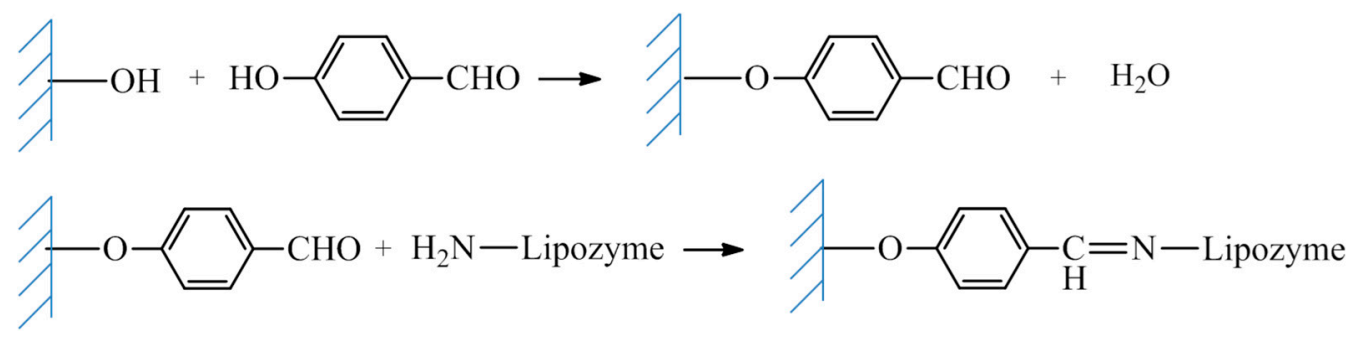

Scheme 2. Solid phase synthesis, step by step, for the immobilization of the enzyme through the $\varepsilon$-amino groups of the lysine residues. In Step 1, surface OH groups of the supported Sepiolite $/ \mathrm{AlPO}_{4}$ are activated by microwave heating with p-hydroxybenzaldehyde; before covalent immobilization of the enzyme through the $\varepsilon$-amino group of lysine residues (step 2). 


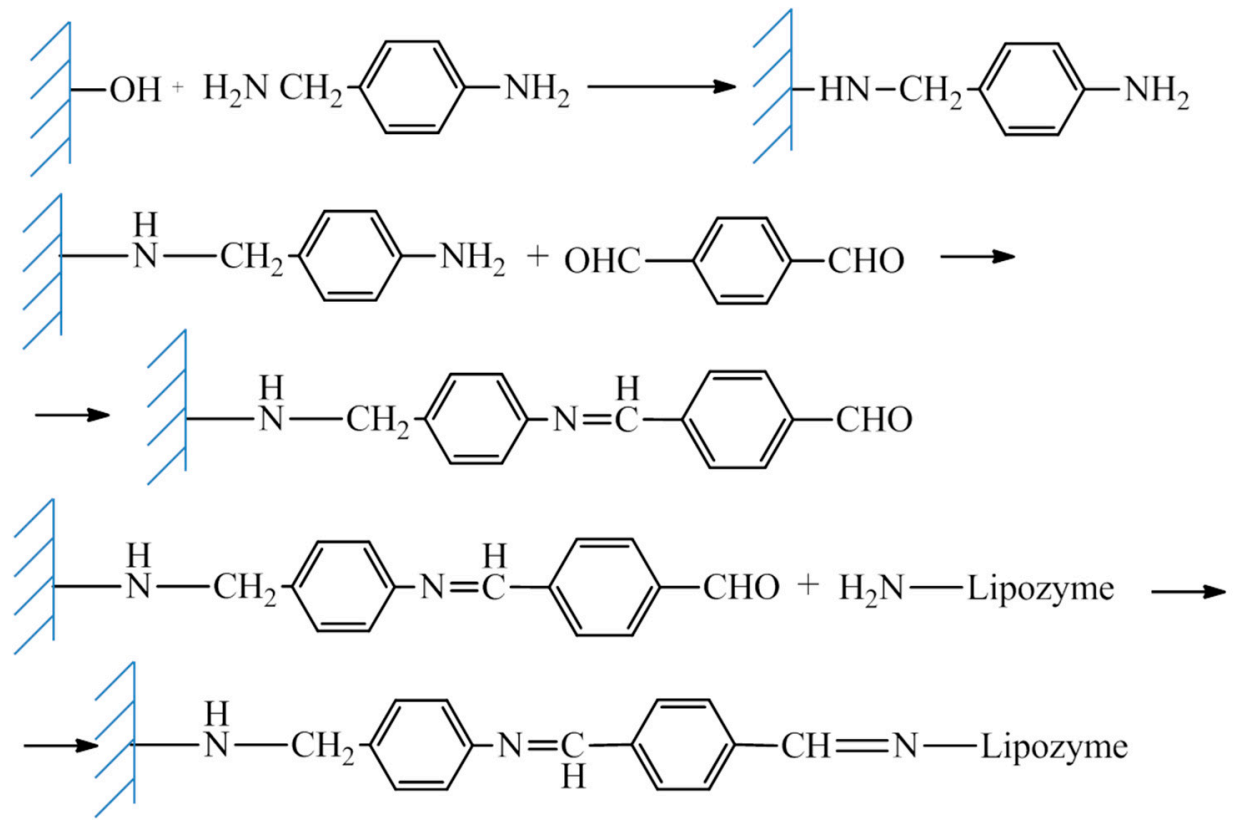

a)

b)

c)

Scheme 3. Solid phase synthesis, step by step, for the immobilization of the enzyme through the $\varepsilon$-amino groups of the lysine residues. In Step 1 , surface $\mathrm{OH}$ groups of the supported $\mathrm{AlPO}_{4} /$ sepiolite are activated by microwave heating with 4-aminobenzylamine; In Step 2, tereftaldicarboxaldehyde is reacted through imines bonds also obtained by microwave heating; Finally, in Step 3 covalent immobilization of the enzyme is obtained through the $\varepsilon$-amino group of lysine residues. It must be clarified that water is formed in steps (a)-(c).

Figure 2 shows the inorganic supports employed to immobilize the Lipozyme RM IM. As can be seen, despite the fact $1 \mathrm{~g}$ of sepiolite was employed instead of $0.2 \mathrm{~g}$ of the rest of the solids, the final volume was similar for all the supports.

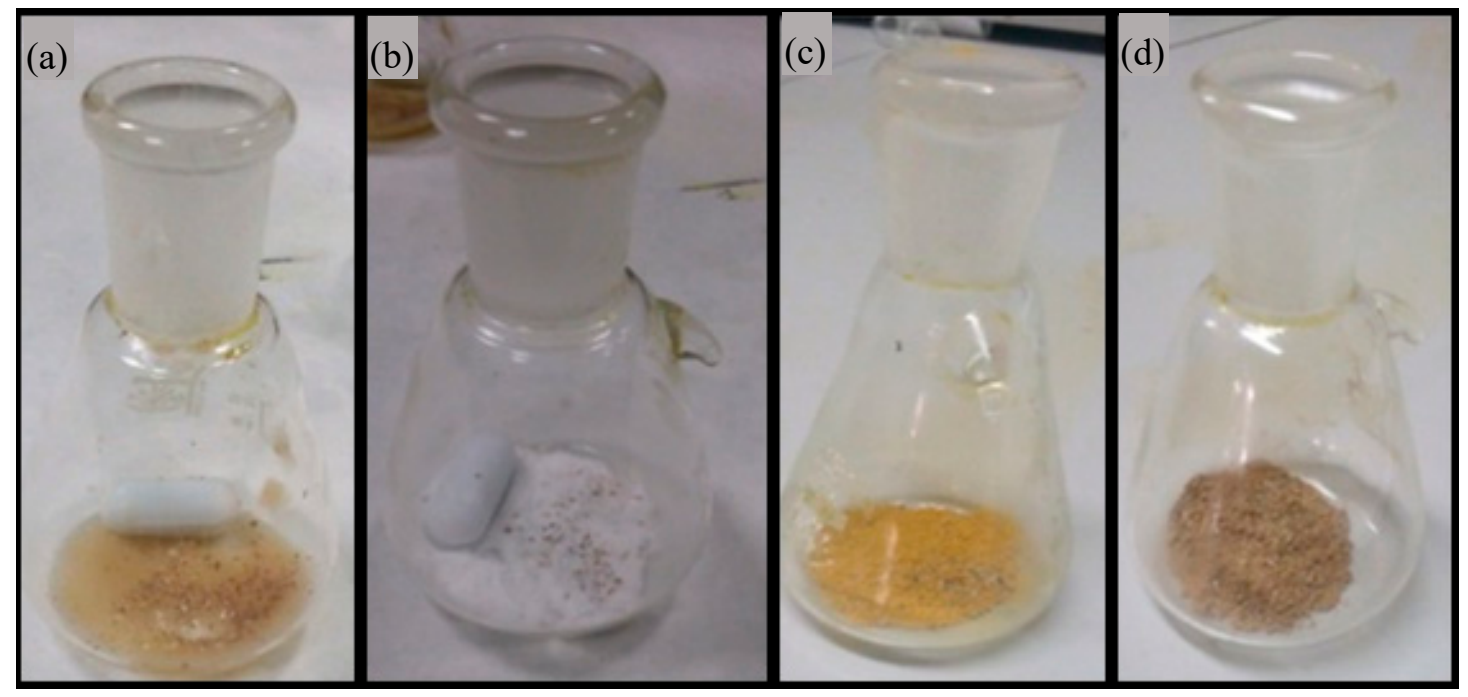

Figure 2. Inorganic supports used to immobilize Lipozyme RM IM: (a) demineralized sepiolite, (b) silica gel, (c) $\mathrm{AlPO}_{4}$ / sepiolite activated with 4-aminobenzylamine and terephthalato dicarboxaldehyde (d) $\mathrm{AlPO}_{4} /$ sepiolite activated with $p$-hydroxybenzaldehyde.

\subsection{Ethanolisis Reactions}

The transesterification reactions of sunflower oil were carried out according to the experimental procedure previously described [26]. Briefly, a $25 \mathrm{~mL}$ volume round bottom flask was immersed in a 
thermostatic bath in which temperature and stirring speed were controlled. The temperature was set to $35^{\circ} \mathrm{C}$ whereas the stirring speed was set at $700 \mathrm{rpm}$ to avoid mass transfer limitations. In a typical run, $9.4 \mathrm{~g}(12 \mathrm{~mL}, 0.01 \mathrm{~mol})$ of sunflower oil was introduce in the batch reactor together with variable oil/ethanol volume ratio, corresponding to a molar ratio between $1 / 4$ and $1 / 6$, different amounts of supported Lipozyme RM and also different amounts of $\mathrm{NaOH} 10 \mathrm{~N}(0-75 \mu \mathrm{L})$. Blank experiments in presence of the highest quantity of $\mathrm{NaOH} 10 \mathrm{~N}$ solution were performed to rule out a potential contribution from the homogeneous $\mathrm{NaOH}$ catalyzed reaction. In these blank experiments, less than $10 \%$ of conversion was obtained, indicating that the homogenous catalysis contribution is negligible under the investigated conditions. At the end of the reaction, the biocatalyst was employed without any treatment, in order to simulate the operational conditions employed in the industry. Thus, by simple decanting for half an hour, the biocatalyst is maintained at the bottom of the flask and the product is retired. Then, a new charge of reactants is added and the reaction is launched again.

\subsection{Analytical Method}

Reaction products were monitored by capillary column gas chromatography, using a 5890 series II instrument (Hewlett-Packard, Palo Alto, California, USA) equipped with a flame ionization detector (FID) and an HT5 capillary column $(25 \mathrm{~m} \times 0.32 \mathrm{~mm} \times 0.10 \mu \mathrm{m})$, using $n$-hexadecane (cetane) as internal standard. The heating ramp was: 50 to $200{ }^{\circ} \mathrm{C}$ at a rate of $7{ }^{\circ} \mathrm{C} / \mathrm{min}$, followed by another ramp from 200 to $360{ }^{\circ} \mathrm{C}$ at a rate of $15{ }^{\circ} \mathrm{C} / \mathrm{min}$, maintaining the oven temperature at $360{ }^{\circ} \mathrm{C}$ for $10 \mathrm{~min}$ [29]. The quantification of the ethyl esters (FAEE), monoglycerides (MG), diglycerides (DG) and triglycerides (TG) allow to determine the Conversion, i.e., Conv = FAEE + MG + DG, whereas the Selectivity is calculated as the sum of FAEE + MG. The differentiation between both parameters is determined by the similarity of the FAEE and MG with the standard n-hexadecane. Therefore, it represents the proportion of biofuel directly comparable with fossil fuels.

\subsection{Determination of Kinematic Viscosity}

The kinematic viscosity has been measured in an Ostwald-Cannon-Fenske capillary viscometer (Proton Routine Viscometer 33200, size 150, Proton Technology AB, Sjäåkravägen 28, SE-564 31 Bankeryd, Sweden), determining the time required for a certain volume of liquid to pass between two marked points on the instrument, placed in an upright position. From the flow time $(\mathrm{t})$, expressed in seconds, we obtain the kinematic viscosity expressed in centistokes, $v=C \cdot t$, where $C$ is the calibration constant of the measurement system in $\mathrm{mm}^{2} / \mathrm{s}^{2}$, which is specified by the manufacturer $(0.040350$ $\mathrm{mm}^{2} / \mathrm{s}^{2}$ at $40{ }^{\circ} \mathrm{C}$, in this case). All measures have been carried out in duplicate and are presented as the average of both, proving that the variation is below $0.35 \%$ between measures, as required by the standard American Society for Testing and Materials ASTM D2270-79 method for the calculating viscosity index from kinematic viscosity at 40 and $100{ }^{\circ} \mathrm{C}$.

\subsection{Experimental Design}

The effect of process parameters in the enzymatic transesterification reaction and the optimum conditions for the selectivity and viscosity were studied using a multifactorial design of experiments

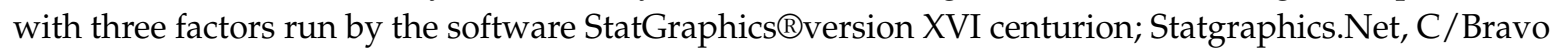
Murillo 350, $1^{\circ}, 28020$ Madrid, Spain. Two of the variables were studied at three levels and the other one at two levels (Table 1), giving us 36 runs. The experiments were performed in random order. The experimental parameters selected for this study were immobilized lipase amount, oil/ethanol molar ratio and $\mathrm{NaOH} 10 \mathrm{~N}$ amount. Table 1 shows the coded and actual values of the process parameters used in the design matrix. 
Table 1. Process parameters in factorial design: coded and actual values.

\begin{tabular}{ccccc}
\hline \multirow{2}{*}{ Variables } & Unit & \multicolumn{3}{c}{ Levels } \\
\cline { 3 - 5 } & & $\mathbf{- 1}$ & $\mathbf{0}$ & $\mathbf{1}$ \\
\hline Immobilized Lipozyme RM IM & $\mathrm{g}$ & 0.01 & 0.02 & 0.03 \\
Oil/ethanol ratio $(v / v)$ & $\mathrm{mL} / \mathrm{mL}$ & $12 / 2.9$ & - & $12 / 3.5$ \\
NaOH 10N amount & $\mu \mathrm{L}$ & 25 & 37.5 & 50 \\
\hline
\end{tabular}

As can be seen in Table 1, the ranges studied are the following: weight of Lipozyme RM $\mathrm{IM}$, from 0.01 to $0.03 \mathrm{~g}$, oil/ethanol volume ratio between $12 / 2.9$ to $12 / 3.5 \mathrm{~mL} / \mathrm{mL}$ (equivalent to molar ratios from $1 / 4$ to $1 / 6$, approximately) and the amount of $10 \mathrm{~N} \mathrm{NaOH}$ between 25 and $50 \mu \mathrm{L}$. Each experiment is done in triplicate to ensure about the reproducibility of each reaction and improve the model.

\subsection{Statistical Analysis}

The experimental data obtained from experimental design were analyzed by RSM [29,30]. A mathematical model, following a second-order polynomial equation, was developed to describe the relationships between the predicted response variable (selectivity or viscosity) and the independent variables of reaction conditions, as shown in Equation (1), where y is the predicted response variable; $\beta_{0}, \beta i, \beta i i, \beta i j$ are the intercept, linear, quadratic and interaction constant coefficients of the model, respectively; $X i, X j(i=1,3 ; j=1,3 ; i \neq j)$ represent the coded independent variables (reaction conditions):

$$
y=\beta_{0}+\sum_{i=1}^{3} \beta_{i} X_{i}+\sum_{i=1}^{3} \beta_{i i} X_{i}^{2}+\sum \sum_{i<j=1}^{3} \beta_{i j} X_{i} X_{j}
$$

Response surface plots were developed using the fitted quadratic polynomial equation obtained from regression analysis, holding one of the independent variables at constant values corresponding to the stationary point and changing the order two variables. The quality of the fit of the polynomial model equation was evaluated by the coefficient of determination $R^{2}$. Likewise, its regression coefficient significance was checked with F-test. Confirmatory experiments were carried out to validate the model, using combinations of independent variables which were not part of the original experimental design, but included in the experimental region.

\section{Results and Discussions}

\subsection{Immobilization of the Commercial Biocatalyst Lipozyme RM IM on an Inorganic Support}

Table 2 shows the conversion and selectivity values obtained in the ethanolysis reaction with the Lipozyme RM IM over all the different supports here studied, as well as the viscosity of the biofuel synthesized.

Table 2. Ethanolysis reactions with Lipozyme RM IM immobilized on different inorganic supports, under the standard experimental reaction conditions: $12 \mathrm{~mL}$ of sunflower oil, $3.5 \mathrm{~mL}$ of absolute ethanol, at a temperature of $35^{\circ} \mathrm{C}, 25 \mu \mathrm{L}$ of $10 \mathrm{~N}$ aqueous solution of $\mathrm{NaOH}, 0.01 \mathrm{~g}$ of Lipozyme RM $\mathrm{IM}, 2 \mathrm{~h}$ reaction times and an agitation of $700 \mathrm{rpm}$, and the indicated amounts of support.

\begin{tabular}{cccc}
\hline Support & Viscosity (cSt) & Conversion (\%) & Selectivity (\%) \\
\hline Unsupported Lipozyme & 7.9 & 100 & 62.4 \\
Lipo-Sep & 18.8 & - & - \\
Lipo-Silica & 11.6 & 83.0 & 31.4 \\
${\text { Lipo-1Sep } / \mathrm{AlPO}_{4}}_{\text {Lipo-2Sep/AlPO }}$ & 23.7 & $1-$ & $1-$ \\
\hline
\end{tabular}

${ }^{1}$ The two initial phases of the reaction mixture (oil and ethanol) are kept separate, an unambiguous sign of inactivity in the reaction. 
As can be seen, the covalent immobilization of the Lipozyme RM IM on Sepiolite support, independently on the procedure employed, produce its complete deactivation. It seems that the presence of functional groups that make possible the covalent immobilization of the lipase, cause the deactivation of its active site somehow. Likewise, the adsorption of the Lipozyme on the demineralized sepiolite also caused the deactivation of the lipase. However, if the Lipozyme is physically adsorbed on silica-gel, reasonably good results are obtained. This immobilization would be well-founded by a physical interaction between the microporous anion exchange resins, in which the lipases is already immobilized, and the silica support. Thus, the interaction allowed increase the low density of the organic polymer without affect the actives sites of the lipase. In order to corroborate the economic feasibility of the lipase immobilization procedure, the performance of the lipase after different reuses must be evaluated. Figure 3 shows the conversion, selectivity and the viscosity of the biofuel obtained, after 15 successive reactions, over the Lipo-silica biocatalyst. As can be seen, the stability of the Lipo-silica is outstanding. In fact, even after the 15th reuse, the conversion and the selectivity are pretty similar to that obtained after the first use. Furthermore, the viscosity of the biofuel obtained is the same for every reaction $(10.5 \pm 0.5 \mathrm{cSt})$. These results are very encouraging, above all if we compare it with those obtained with the Lipozyme without immobilize, with which only six reuses before a total loss of the activity is observed [26]. Furthermore, considering the operative aspects at plant scale, the Lipo-silica catalyst only requires that the product of the reaction be extracted from the reactor and then, a new charge of reactants can be added for starting the subsequent reaction. For its part, the Lipozyme without immobilization requires a centrifugation process, much more difficult from an operational point of view.

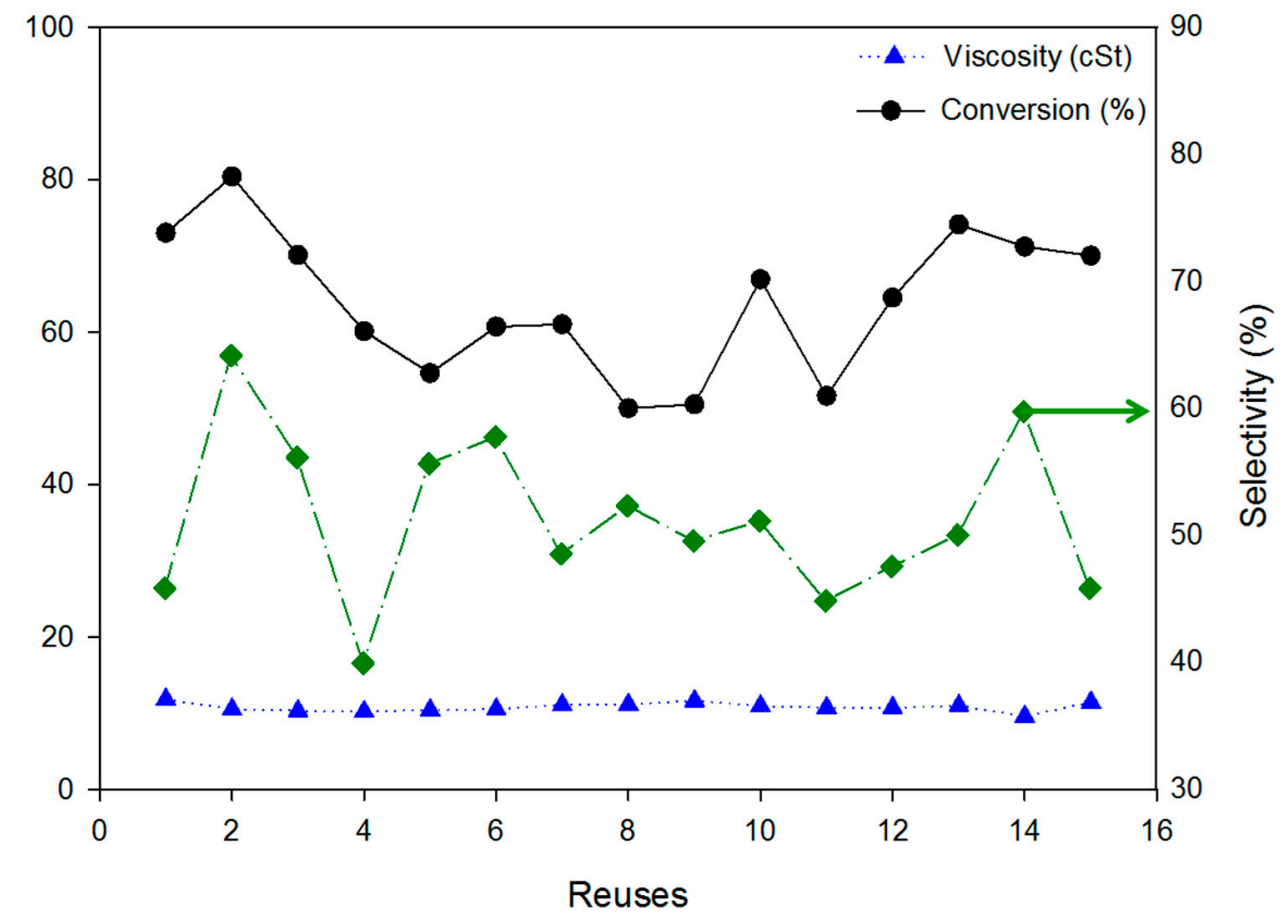

Figure 3. Reuse of the Rhizomucor miehei system of Novozyme (Lipozyme RM IM) immobilized with silica gel (Lipo-silica), by simple physical attraction, operating under the standard conditions indicated in Table 2.

\subsection{Analysis of Variance (ANOVA) and Optimization of the Reaction Parameters by RSM}

Given the good behavior of the Lipo-silica biocatalytic system in the Ecodiesel production, a multilevel factorial experimental design has been carried out in order to analyze the effects of experimental parameters in the enzymatic selective ethanolysis reaction of sunflower oil. In this sense, on the basis of previous researches [27], the weight of Lipo-silica, the oil/ethanol volume ratio 
and the amount of $10 \mathrm{~N} \mathrm{NaOH}$ have been selected as the most relevant parameters. To evaluate the magnitude of these parameters on the selectivity of the partial ethanolysis reaction of sunflower oil, some limits have been set for each variable, as indicated in Table 1. It is also intended to determine the influence of these variables on the kinematic viscosity of the final mixture, given that the viscosity is the parameter which determines whether the biofuel obtained can be employed in current engines. Therefore, the experimental design consists of 18 experiments (runs) carried out in duplicate and in a random way to minimize possible errors. The sequence of the performed experiments is shown in Table 3.

Table 3. Experiments matrix of factorial design and the response obtained for viscosity and selectivity.

\begin{tabular}{|c|c|c|c|c|c|}
\hline \multirow{2}{*}{ Run } & \multicolumn{3}{|c|}{ Studied Variables } & \multicolumn{2}{|c|}{ Output Variables } \\
\hline & $\begin{array}{l}\text { Amount Lipozyme } \\
\text { RM IM (g) }\end{array}$ & $\begin{array}{c}\text { Oíl/ethanol } \\
\text { ratio (mol/mol) }\end{array}$ & $\begin{array}{l}\text { Amount of } 10 \\
\mathrm{~N} \mathrm{NaOH}(\mu \mathrm{L})\end{array}$ & Viscosity (cSt) & Selectivity (\%) \\
\hline 1 & 1 & -1 & 0 & 11.36 & 39.7 \\
\hline 2 & 1 & 1 & -1 & 10.16 & 50.1 \\
\hline 3 & -1 & 1 & 1 & 9.98 & 67.9 \\
\hline 4 & 0 & 1 & -1 & 9.88 & 49.8 \\
\hline 5 & -1 & -1 & 0 & 11.48 & 45.3 \\
\hline 6 & 1 & -1 & 1 & 11.56 & 47.6 \\
\hline 7 & -1 & 1 & -1 & 10.56 & 51.4 \\
\hline 8 & -1 & 1 & 0 & 9.09 & 55.2 \\
\hline 9 & 0 & -1 & -1 & 11.84 & 40.7 \\
\hline 10 & 0 & -1 & 0 & 11.52 & 41.1 \\
\hline 11 & 0 & 1 & 1 & 8.92 & 69.8 \\
\hline 12 & 1 & 1 & 0 & 10.14 & 51.6 \\
\hline 13 & -1 & -1 & 1 & 10.82 & 52.7 \\
\hline 14 & 0 & 1 & 0 & 9.31 & 56.2 \\
\hline 15 & 0 & -1 & 1 & 9.98 & 48.7 \\
\hline 16 & 1 & 1 & 1 & 9.86 & 67.1 \\
\hline 17 & 1 & -1 & -1 & 11.64 & 35.1 \\
\hline 18 & -1 & -1 & -1 & 12.29 & 43.2 \\
\hline \multicolumn{6}{|c|}{ Repeated experiments } \\
\hline 19 & 1 & 1 & 1 & 9.94 & 58.7 \\
\hline 20 & 0 & -1 & 1 & 9.94 & 53.1 \\
\hline 21 & 1 & -1 & 1 & 11.09 & 44.4 \\
\hline 22 & -1 & 1 & 1 & 10.18 & 64.5 \\
\hline 23 & 1 & -1 & -1 & 12.21 & 34.5 \\
\hline 24 & -1 & 1 & 0 & 10.01 & 60.5 \\
\hline 25 & -1 & -1 & 0 & 11.52 & 45.7 \\
\hline 26 & -1 & 1 & -1 & 10.01 & 54.7 \\
\hline 27 & 0 & 1 & -1 & 8.89 & 56.6 \\
\hline 28 & -1 & -1 & -1 & 11.56 & 36.8 \\
\hline 29 & 0 & 1 & 1 & 9.53 & 61.8 \\
\hline 30 & 0 & 1 & 0 & 9.73 & 59.7 \\
\hline 31 & 0 & -1 & 0 & 10.44 & 44.3 \\
\hline 32 & 1 & 1 & 0 & 10.88 & 54.3 \\
\hline 33 & 0 & -1 & -1 & 11.26 & 33.2 \\
\hline 34 & 1 & -1 & 0 & 11.48 & 37.4 \\
\hline 35 & -1 & -1 & 1 & 10.26 & 50.2 \\
\hline 36 & 1 & 1 & -1 & 10.03 & 50.1 \\
\hline
\end{tabular}

From these data, we are able to determine the correlation between the experimental variables here studied with the output variables (selectivity and kinematic viscosity), by using the Statgraphics software and a multivariate statistical analysis (ANOVA). As can be seen in Tables 4 and 5 , the quadratic polynomial model was highly significant, allowing us to understand which variables have a greater impact on the selectivity and kinematic viscosity. 
Table 4. Analysis of variance (ANOVA) for selectivity.

\begin{tabular}{cccccc}
\hline Source & Sum of Squares & Freedom Degree & Mean Square & F-Ratio & $p$-Value \\
\hline A: Amount Lipozyme RM & 137.76 & 1 & 137.76 & 17.05 & 0.0003 \\
B: Ratio oil/Ethanol & 1969.88 & 1 & 1969.88 & 243.81 & 0.0000 \\
C: Amount NaOH 10N & 941.254 & 1 & 941.254 & 116.50 & 0.0000 \\
AA & 13.6068 & 1 & 13.6068 & 1.68 & 0.2058 \\
AB & 6.93375 & 1 & 6.93375 & 0.86 & 0.3628 \\
AC & 0.09 & 1 & 0.09 & 0.01 & 0.9168 \\
BC & 0.63375 & 1 & 0.63375 & 0.08 & 0.7816 \\
CC & 23.0068 & 1 & 23.0068 & 2.85 & 0.1035 \\
blocks & 4.48028 & 1 & 4.48028 & 0.55 & 0.4632 \\
Total error & 210.071 & 26 & 8.07964 & & \\
Total (corr.) & 3307.72 & 35 & & &
\end{tabular}

Table 5. Analysis of variance (ANOVA) for viscosity.

\begin{tabular}{cccccc}
\hline Source & Sum of Squares & Freedom Degree & Mean Square & F-Ratio & $p$-Value \\
\hline A: Amount Lipozyme RM & 0.279504 & 1 & 0.279504 & 1.59 & 0.2189 \\
B: Ratio oil/Ethanol & 17.5701 & 1 & 17.5701 & 99.77 & 0.0000 \\
C: Amount NaOH 10N & 2.8497 & 1 & 2.8497 & 16.18 & 0.0004 \\
AA & 3.39301 & 1 & 3.39301 & 19.27 & 0.0002 \\
AB & 0.00220417 & 1 & 0.00220417 & 0.01 & 0.9118 \\
AC & 0.158006 & 1 & 0.158006 & 0.90 & 0.3523 \\
BC & 1.51504 & 1 & 1.51504 & 8.60 & 0.0069 \\
CC & 0.0325125 & 1 & 0.0325125 & 0.18 & 0.6710 \\
Blocks & 0.0568028 & 1 & 0.0568028 & 0.32 & 0.5750 \\
Total error & 4.57882 & 26 & 0.176109 & & \\
Total (corr.) & 30.4357 & 35 & &
\end{tabular}

The correlation coefficients values, $\mathrm{R}^{2}$, were 0.849 and 0.936 for selectivity and kinematic viscosity, respectively. These results imply a good fit between models and experimental data in Pareto graphics (Figure 4). Furthermore, the adjusted correlation coefficients $\mathrm{R}^{2}$ (Adj) were 0.805 for selectivity and 0.917 for selectivity and kinematic viscosity (Tables 4 and 5). The results here collected pointed out that all the parameters studied has an important influence on the selectivity of the process, specially the oil/ethanol ratio $(v / v)$ and. However, according to the kinematic viscosity, the most relevant parameters are the oil/ethanol ratio $(v / v)$ and the amount of $10 \mathrm{~N} \mathrm{NaOH}$ employed $(p<0.05)$.

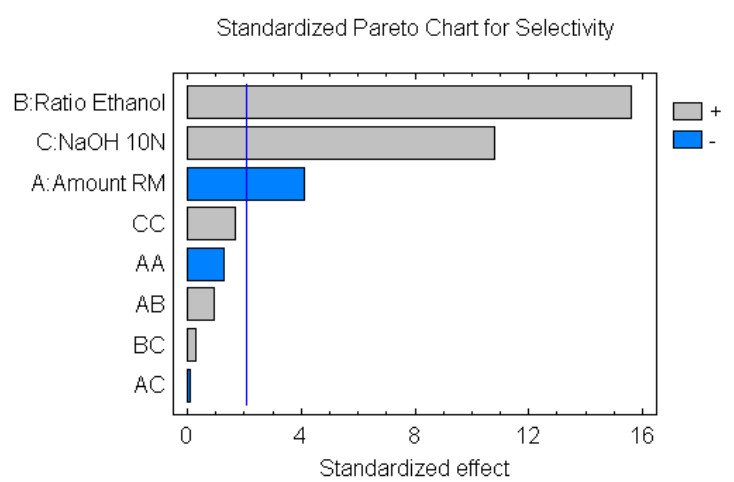

(a)

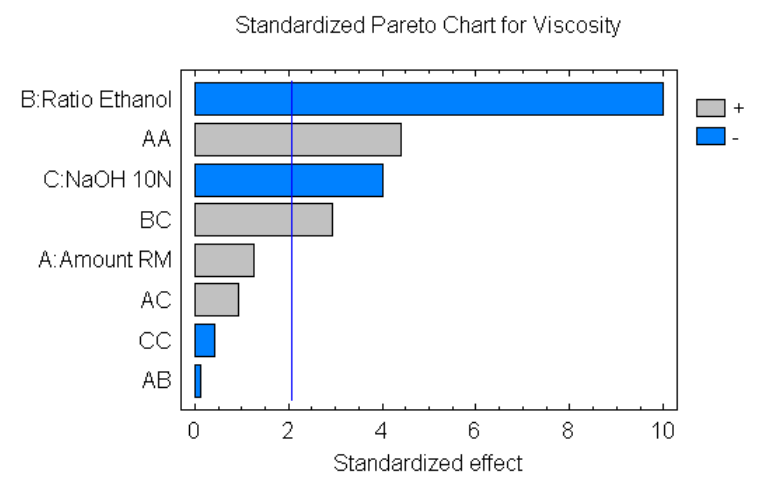

(b)

Figure 4. Pareto graphics: (a) for selectivity and (b) for viscosity.

Likewise, if we represent the influence of the different factors on selectivity and kinematic viscosity (Figure 5), it is easy to deduce that the higher the positive slope, the higher the effect of the factor. Thus, 
it can be seen in Figure 5a,b, how the oil/ethanol ratio is the parameter with the highest statistical significance not only on the selectivity but also on the kinematic viscosity.

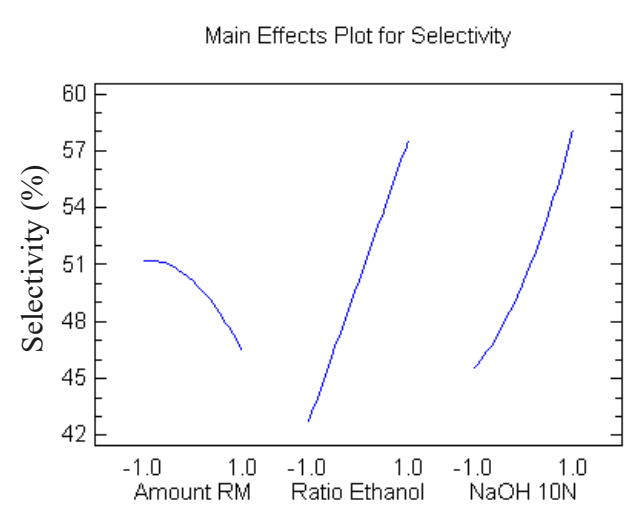

(a)

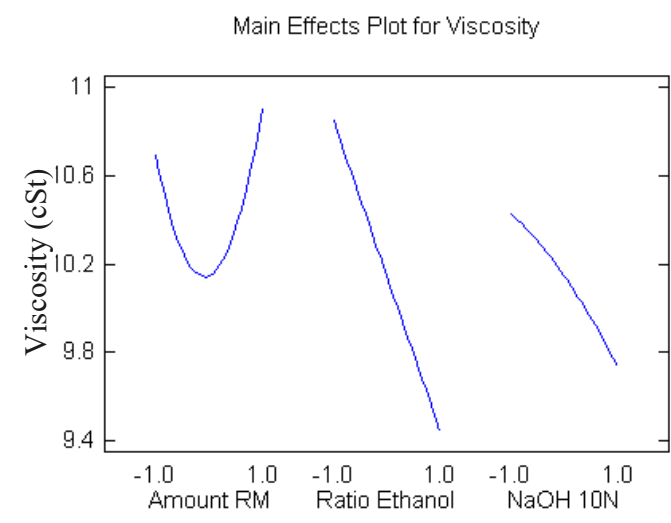

(b)

Figure 5. Graphical representation of the different factors on: (a) selectivity; (b) on the viscosity.

Furthermore, the software also allows obtaining equations, after the elimination of non-influent parameters in the model, for selectivity and kinematic viscosity, whose $R^{2}$ values were 0,741 and 0.873 , respectively. The equations obtained were quite simpler as compared to initial ones. These equations describe the created model and gives solutions for the dependent variable based on the independent variable combinations, whether they are or not significant in the response. Thus, considering that $\mathrm{R}$ is the Oil/Ethanol ratio $(v / v)$; $\mathrm{N}$ is the amount of $10 \mathrm{~N} \mathrm{NaOH}$ in $\mu \mathrm{L}$ and $\mathrm{A}$, amount of Lipozyme RM, we have the following equations:

$$
\begin{aligned}
& \text { Selectivity }=50.1194+7.39722 \mathrm{R}+0.1625 \mathrm{RN}-1.30417 \mathrm{~A}^{2} \\
& \text { Viscosity }=10.1458+0.107917 \mathrm{~A}-0.698611 \mathrm{R}+0.65125 \mathrm{~A}^{2}
\end{aligned}
$$

The surface plots described by the regression model were drawn to display the effects of the independent variables on selectivity and kinematic viscosity, Figure 6. This model shows that the optimum values for the parameters to maximize selectivity were: low lipase amount $(0.012 \mathrm{~g})$, high oil/ethanol molar ratio (1/6) and high $10 \mathrm{~N} \mathrm{NaOH}$ amount $(50 \mu \mathrm{L})$. Regarding the optimum values to maximize the viscosity: lipase amount $(0.017 \mathrm{~g})$, which is a bit higher than that for selectivity, oil/ethanol molar ratio (1/6) and amount of $10 \mathrm{~N} \mathrm{NaOH}(50 \mu \mathrm{L})$. Thus, a selectivity value around $66 \%$ and viscosity around $9.5 \mathrm{cSt}$ can be achieved under these conditions. The biofuel obtained at these conditions is feasible to be employed in a mix with diesel fuel in blends of $50 \%$, or even more, falling within the acceptance limits of the EN 14214.

To validate the proposed models, a serie of experiments, whose conditions are among the range of the studied variables, has been carried out. Thus, the experimental values of selectivity and kinematic viscosity have been collected in Table 6 . Furthermore, a comparison between the experimental values and the theoretical ones has been also compiled. As can be seen in Figure 7, a good adjustment of the model, with values of $\mathrm{R}^{2}$ of $84.955 \%$, for Selectivity and $93.649 \%$ for Viscosity, has been obtained, corroborating the good correlation between the experimental values and those predicted by the model. 


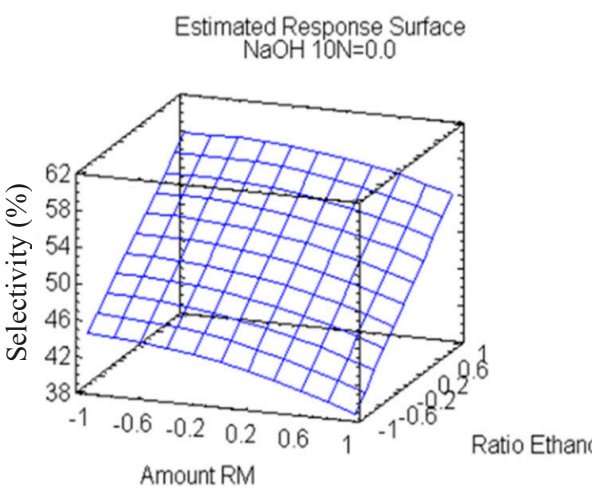

Contours of Estimated Response Surface

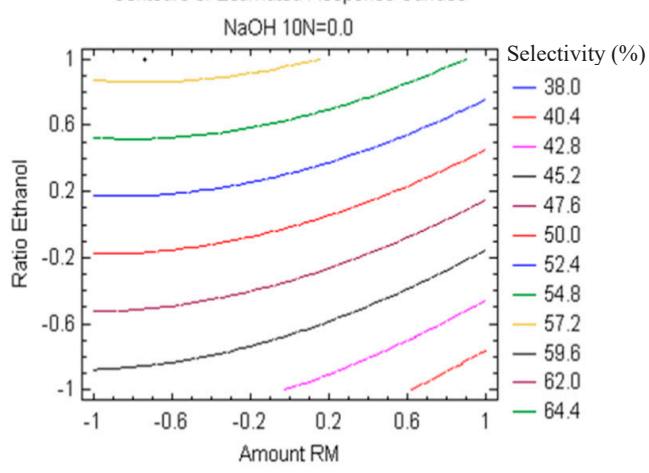

(a)

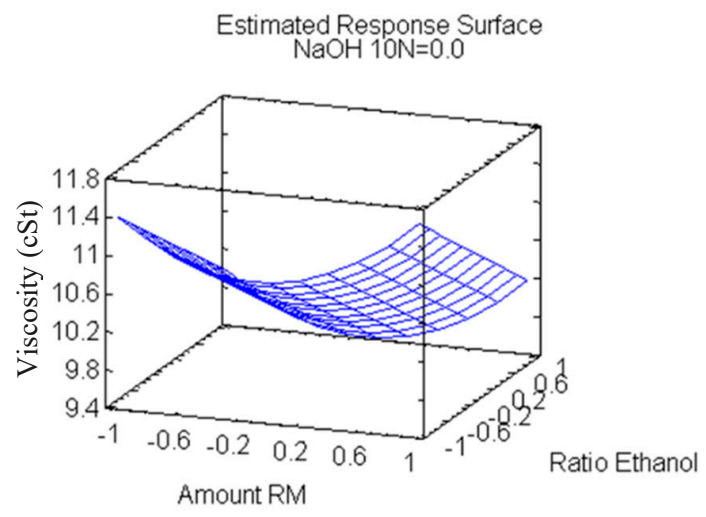

Contours of Estimated Response Surface $\mathrm{NaOH} 10 \mathrm{~N}=0.0$

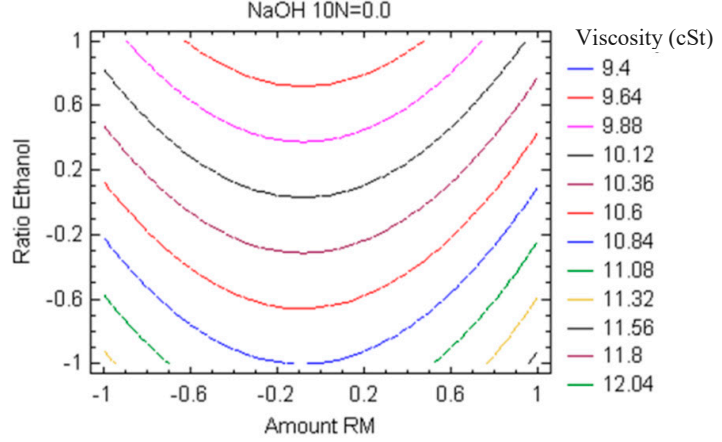

(b)

Figure 6. Graphic representation of the different factors on: (a) selectivity; (b) viscosity.

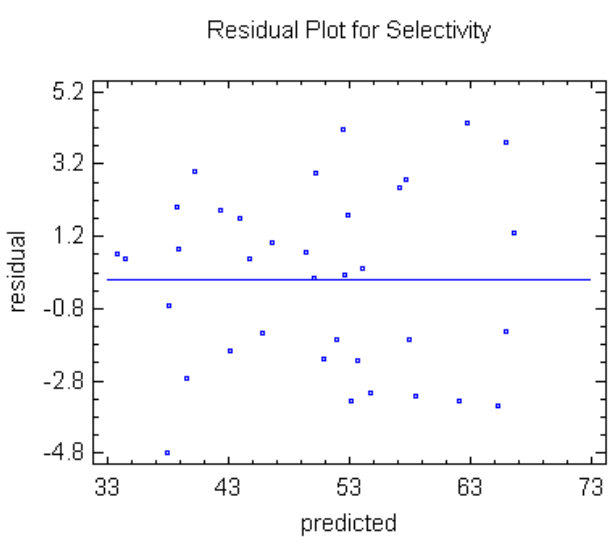

(a)

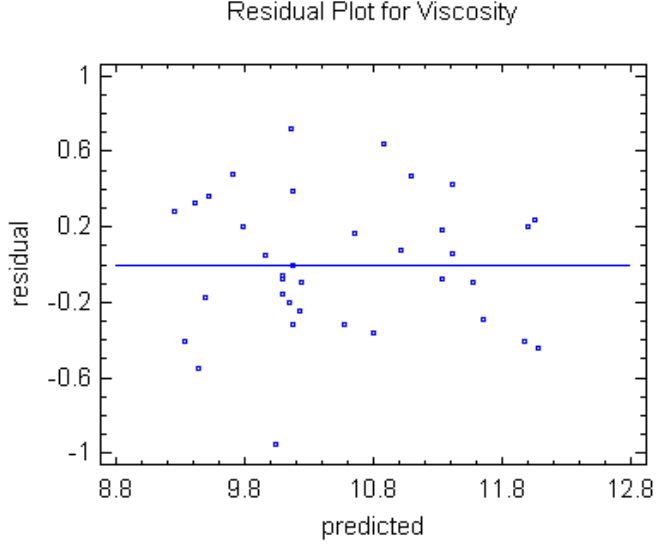

(b)

Figure 7. Probability graphs of (a) Selectivity and (b) Viscosity.

Therefore, it can be concluded that the model created to correlate the reaction parameters (amount of lipase, ratio oil/ethanol and amount of $\mathrm{NaOH} 10 \mathrm{~N}$ aqueous solution) with the selectivity and the kinematic viscosity is acceptable, since it is able to explain the variability produced in these experimental parameters. 
Table 6. Experiments matrix of factorial design and the response obtained for selectivity and viscosity. Experimental values obtained for each reaction of the experimental design for the Selectivity and Kinematic Viscosity at $40{ }^{\circ} \mathrm{C}$, collected in Table 3, compared to the values obtained when applying the theoretical model proposed.

\begin{tabular}{|c|c|c|c|c|c|c|c|}
\hline \multirow[b]{2}{*}{ Run } & \multicolumn{3}{|c|}{ Studied Variables } & \multicolumn{2}{|c|}{ Selectivity (\%) } & \multicolumn{2}{|c|}{ Viscosity (cSt) } \\
\hline & $\begin{array}{c}\text { Amount Lipozyme } \\
\text { RM IM (g) }\end{array}$ & $\begin{array}{l}\text { Oíl/ethanol } \\
\text { Ratio }\end{array}$ & $\begin{array}{l}\text { Amount of } \\
10 \mathrm{~N} \mathrm{NaOH}\end{array}$ & Exp. Value & Predicted & Exp. Value & Predicted \\
\hline 1 & 1 & -1 & 0 & 39.7 & 38.8375 & 11.36 & 11.6529 \\
\hline 2 & 1 & 1 & -1 & 50.1 & 50.0528 & 10.16 & 10.1667 \\
\hline 3 & -1 & 1 & 1 & 67.9 & 66.6194 & 9.98 & 9.7834 \\
\hline 4 & 0 & 1 & -1 & 49.8 & 53.1403 & 9.88 & 9.51653 \\
\hline 5 & -1 & -1 & 0 & 45.3 & 44.7042 & 11.48 & 11.4179 \\
\hline 6 & 1 & -1 & 1 & 47.6 & 46.5583 & 11.56 & 11.0927 \\
\hline 7 & -1 & 1 & -1 & 51.4 & 53.6194 & 10.56 & 10.1688 \\
\hline 8 & -1 & 1 & 0 & 55.2 & 58.4236 & 9.09 & 10.0399 \\
\hline 9 & 0 & -1 & -1 & 40.7 & 38.6708 & 11.84 & 11.4162 \\
\hline 10 & 0 & -1 & 0 & 41.1 & 43.075 & 11.52 & 10.8842 \\
\hline 11 & 0 & 1 & 1 & 69.8 & 65.9903 & 8.92 & 9.32986 \\
\hline 12 & 1 & 1 & 0 & 51.6 & 54.7069 & 10.14 & 10.2365 \\
\hline 13 & -1 & -1 & 1 & 52.7 & 52.575 & 10.82 & 10.659 \\
\hline 14 & 0 & 1 & 0 & 56.2 & 57.8694 & 9.31 & 9.48694 \\
\hline 15 & 0 & -1 & 1 & 48.7 & 50.8708 & 9.98 & 10.2246 \\
\hline 16 & 1 & 1 & 1 & 67.1 & 62.7528 & 9.86 & 10.1788 \\
\hline 17 & 1 & -1 & -1 & 35.1 & 34.5083 & 11.64 & 12.0856 \\
\hline 18 & -1 & -1 & -1 & 43.2 & 40.225 & 12.29 & 12.0494 \\
\hline \multicolumn{8}{|c|}{ Repeated experiments } \\
\hline 19 & 1 & 1 & 1 & 58.7 & 62.0472 & 9.94 & 10.0994 \\
\hline 20 & 0 & -1 & 1 & 53.1 & 50.1653 & 9.94 & 10.1451 \\
\hline 21 & 1 & -1 & 1 & 44.4 & 45.8528 & 11.09 & 11.0133 \\
\hline 22 & -1 & 1 & 1 & 64.5 & 65.9139 & 10.18 & 9.70396 \\
\hline 23 & 1 & -1 & -1 & 34.5 & 33.8028 & 12.21 & 12.0062 \\
\hline 24 & -1 & 1 & 0 & 60.5 & 57.7181 & 10.01 & 9.96042 \\
\hline 25 & -1 & -1 & 0 & 45.7 & 43.9986 & 11.52 & 11.3385 \\
\hline 26 & -1 & 1 & -1 & 54.7 & 52.9139 & 10.01 & 10.0894 \\
\hline 27 & 0 & 1 & -1 & 56.6 & 52.4347 & 8.89 & 9.43708 \\
\hline 28 & -1 & -1 & -1 & 36.8 & 39.5194 & 11.56 & 11.9699 \\
\hline 29 & 0 & 1 & 1 & 61.8 & 65.2847 & 9.53 & 9.25042 \\
\hline 30 & 0 & 1 & 0 & 59.7 & 57.1639 & 9.73 & 9.4075 \\
\hline 31 & 0 & -1 & 0 & 44.3 & 42.3694 & 10.44 & 10.8047 \\
\hline 32 & 1 & 1 & 0 & 54.3 & 54.0014 & 10.88 & 10.1571 \\
\hline 33 & 0 & -1 & -1 & 33.2 & 37.9653 & 11.26 & 11.3368 \\
\hline 34 & 1 & -1 & 0 & 37.4 & 38.1319 & 11.48 & 11.5735 \\
\hline 35 & -1 & -1 & 1 & 50.2 & 51.8694 & 10.26 & 10.5795 \\
\hline 36 & 1 & 1 & -1 & 50.1 & 49.3472 & 10.03 & 10.0873 \\
\hline
\end{tabular}

\section{Conclusions}

In this research work, the immobilization of Lipozyme RM IM, a Rhizomucor miehei lipase, on different supports has been evaluated by its use as biocatalyst in the synthesis of Ecodiesel, a biodiesel-like biofuel obtained by selective transesterification of sunflower oil with ethanol. The best results have been obtained using a commercial silica gel 60 as support, achieving similar results to those obtained over the non-immobilized Lipozyme. Likewise, the optimization of the reaction parameters as well as the influence of these parameters in the enzymatic transesterification has been carried out by a statistical multifactorial design of experiments with three factors run by the Software StatGraphics. The analysis of variance showed that, in order to obtain an improvement in selectivity and kinematic viscosity, the reaction conditions should be an oil/ethanol molar ratio of $1 / 6$ and a high amount of $10 \mathrm{~N} \mathrm{NaOH}, 50 \mu \mathrm{L}$, whereas the amount of lipase employed depends on which parameter wanted to be optimized, i.e., $0.012 \mathrm{~g}$ of lipase to achieve the best selectivity value or 0.017 to achieve the best kinematic viscosity. Furthermore, the quadratic models obtained showed good results in terms of predicting the selectivity and viscosity of the investigated systems, as it was corroborated by experimental reactions. 
The stability of the heterogeneous biocatalysts was studied by successive reactions in order to evaluate the feasibility and economic viability of its application in industrial scale. In this way, by means of simple physical immobilization of the Lipozyme on silica-gel, 15 reuses can be obtained without an evidence of activity loss. This fact allows us to assume that it is possible to perform a much greater number of reuses. These results are very remarkable, taking into account that the commercial Lipozyme RM IM, immobilized in an organic polymer is able to perform only 6 reuses before the total loss of activity.

Besides, an improvement in the operational separation of the biocatalyst from the reaction medium was obtained, since the commercial Lipozyme has to be separated by centrifugation, whereas the supported Lipozyme can be separated by decantation.

Author Contributions: This research article is part of the doctoral thesis of J.C., directed by D.L., and F.M.B., who in general conceived and designed the experiments. C.L., A.A.R., B.H. and R.E. made substantive intellectual contributions to this study, making substantial contributions to conception and design of it, as well as to the acquisition, analysis and interpretation of data. Furthermore, J.C., D.L. and R.E. wrote the paper. All the authors have been also involved in drafting and revising the manuscript, so that everyone has given final approval of the current version to be published in Energies Journal.

Acknowledgments: This research is supported by the MEIC funds (Project ENE 2016-81013-R), Junta de Andalucía and FEDER (P11-TEP-7723), that cover the costs to publish in open access.

Conflicts of Interest: The authors declare no conflict of interest.

\section{References}

1. Ko, C.-H.; Chaiprapat, S.; Kim, L.-H.; Hadi, P.; Hsu, S.-C.; Leu, S.-Y. Carbon sequestration potential via energy harvesting from agricultural biomass residues in Mekong River basin, Southeast Asia. Renew. Sustain. Energy Rev. 2017, 68, 1051-1062. [CrossRef]

2. Joshi, G.; Pandey, J.K.; Rana, S.; Rawat, D.S. Challenges and opportunities for the application of biofuel. Renew. Sustain. Energy Rev. 2017, 79, 850-866. [CrossRef]

3. Sen, B.; Ercan, T.; Tatari, O. Does a battery-electric truck make a difference?-Life cycle emissions, costs, and externality analysis of alternative fuel-powered Class 8 heavy-duty trucks in the United States. J. Clean. Prod. 2017, 141, 110-121. [CrossRef]

4. Nair, S.; Paulose, H. Emergence of green business models: The case of algae biofuel for aviation. Energy Policy 2014, 65, 175-184. [CrossRef]

5. Noh, H.M.; Benito, A.; Alonso, G. Study of the current incentive rules and mechanisms to promote biofuel use in the EU and their possible application to the civil aviation sector. Transp. Res. Part D Transp. Environ. 2016, 46, 298-316. [CrossRef]

6. Winnes, H.; Styhre, L.; Fridell, E. Reducing GHG emissions from ships in port areas. Res. Transp. Bus. Manag. 2015, 17, 73-82. [CrossRef]

7. Russo, D.; Dassisti, M.; Lawlor, V.; Olabi, A. State of the art of biofuels from pure plant oil. Renew. Sustain. Energy Rev. 2012, 16, 4056-4070. [CrossRef]

8. Collet, P.; Lardon, L.; Hélias, A.; Bricout, S.; Lombaert-Valot, I.; Perrier, B.; Lépine, O.; Steyer, J.-P.; Bernard, O. Biodiesel from microalgae-Life cycle assessment and recommendations for potential improvements. Renew. Energy 2014, 71, 525-533. [CrossRef]

9. Dharma, S.; Masjuki, H.; Ong, H.C.; Sebayang, A.; Silitonga, A.; Kusumo, F.; Mahlia, T. Optimization of biodiesel production process for mixed Jatropha curcas-Ceiba pentandra biodiesel using response surface methodology. Energy Convers. Manag. 2016, 115, 178-190. [CrossRef]

10. Talebian-Kiakalaieh, A.; Amin, N.A.S.; Mazaheri, H. A review on novel processes of biodiesel production from waste cooking oil. Appl. Energy 2013, 104, 683-710. [CrossRef]

11. Wadumesthrige, K.; Ara, M.; Salley, S.O.; Ng, K.S. Investigation of lubricity characteristics of biodiesel in petroleum and synthetic fuel. Energy Fuels 2009, 23, 2229-2234. [CrossRef]

12. Aransiola, E.; Ojumu, T.; Oyekola, O.; Madzimbamuto, T.; Ikhu-Omoregbe, D. A review of current technology for biodiesel production: State of the art. Biomass Bioenergy 2014, 61, 276-297. [CrossRef]

13. Santori, G.; Di Nicola, G.; Moglie, M.; Polonara, F. A review analyzing the industrial biodiesel production practice starting from vegetable oil refining. Appl. Energy 2012, 92, 109-132. [CrossRef] 
14. Quispe, C.A.; Coronado, C.J.; Carvalho, J.A., Jr. Glycerol: Production, consumption, prices, characterization and new trends in combustion. Renew. Sustain. Energy Rev. 2013, 27, 475-493. [CrossRef]

15. Ang, G.T.; Tan, K.T.; Lee, K.T. Recent development and economic analysis of glycerol-free processes via supercritical fluid transesterification for biodiesel production. Renew. Sustain. Energy Rev. 2014, 31, 61-70. [CrossRef]

16. Okoye, P.; Hameed, B. Review on recent progress in catalytic carboxylation and acetylation of glycerol as a byproduct of biodiesel production. Renew. Sustain. Energy Rev. 2016, 53, 558-574. [CrossRef]

17. Luna, D.; Calero, J.; Sancho, E.; Luna, C.; Posadillo, A.; Bautista, F.; Romero, A.; Berbel, J.; Verdugo, C. Technological challenges for the production of biodiesel in arid lands. J. Arid Environ. 2014, 102, 127-138. [CrossRef]

18. Calero, J.; Luna, D.; Sancho, E.D.; Luna, C.; Bautista, F.M.; Romero, A.A.; Posadillo, A.; Berbel, J.; Verdugo-Escamilla, C. An overview on glycerol-free processes for the production of renewable liquid biofuels, applicable in diesel engines. Renew. Sustain. Energy Rev. 2015, 42, 1437-1452. [CrossRef]

19. Ilham, Z.; Saka, S. Two-step supercritical dimethyl carbonate method for biodiesel production from Jatropha curcas oil. Bioresour. Technol. 2010, 101, 2735-2740. [CrossRef] [PubMed]

20. Casas, A.; Ruiz, J.R.; Ramos, M.A.J.S.; Pérez, A. Effects of triacetin on biodiesel quality. Energy Fuels 2010, 24, 4481-4489. [CrossRef]

21. Caballero, V.; Bautista, F.M.; Campelo, J.M.; Luna, D.; Marinas, J.M.; Romero, A.A.; Hidalgo, J.M.; Luque, R.; Macario, A.; Giordano, G. Sustainable preparation of a novel glycerol-free biofuel by using pig pancreatic lipase: Partial 1, 3-regiospecific alcoholysis of sunflower oil. Process Biochem. 2009, 44, 334-342. [CrossRef]

22. Luna, D.; Bautista, F.M.; Caballero, V.; Campelo, J.M.; Marinas, J.M.; Romero, A.A. Method for Producing Biodiesel Using Porcine Pancreatic Lipase as an Enzymatic Catalyst. WO Patent 2008009772A1, 24 January 2008.

23. Luna, C.; Luna, D.; Bautista, F.M.; Estevez, R.; Calero, J.; Posadillo, A.; Romero, A.A.; Sancho, E.D. Application of Enzymatic Extracts from a CALB Standard Strain as Biocatalyst within the Context of Conventional Biodiesel Production Optimization. Molecules 2017, 22, 2025. [CrossRef] [PubMed]

24. Luna, C.; Sancho, E.; Luna, D.; Caballero, V.; Calero, J.; Posadillo, A.; Verdugo, C.; Bautista, F.M.; Romero, A.A. Biofuel that keeps glycerol as monoglyceride by 1, 3-selective ethanolysis with pig pancreatic lipase covalently immobilized on AlPO4 support. Energies 2013, 6, 3879-3900. [CrossRef]

25. Verdugo, C.; Luna, D.; Posadillo, A.; Sancho, E.D.; Rodríguez, S.; Bautista, F.; Luque, R.; Marinas, J.M.; Romero, A.A. Production of a new second generation biodiesel with a low cost lipase derived from Thermomyces lanuginosus: Optimization by response surface methodology. Catal. Today 2011, 167, 107-112. [CrossRef]

26. Calero, J.; Verdugo, C.; Luna, D.; Sancho, E.D.; Luna, C.; Posadillo, A.; Bautista, F.M.; Romero, A.A. Selective ethanolysis of sunflower oil with Lipozyme RM IM, an immobilized Rhizomucor miehei lipase, to obtain a biodiesel-like biofuel, which avoids glycerol production through the monoglyceride formation. New Biotechnol. 2014, 31, 596-601. [CrossRef] [PubMed]

27. Luna, C.; Verdugo, C.; Sancho, E.D.; Luna, D.; Calero, J.; Posadillo, A.; Bautista, F.M.; Romero, A.A. A biofuel similar to biodiesel obtained by using a lipase from Rhizopus oryzae, optimized by response surface methodology. Energies 2014, 7, 3383-3399. [CrossRef]

28. Bautista, F.M.; Bravo, M.C.; Campelo, J.M.; García, A.; Luna, D.; Marinas, J.M.; Romero, A.A. Covalent immobilization of porcine pancreatic lipase on amorphous AlPO4 and other inorganic supports. J. Chem. Technol. Biotechnol. 1998, 72, 249-254. [CrossRef]

29. Verdugo, C.; Luque, R.; Luna, D.; Hidalgo, J.M.; Posadillo, A.; Sancho, E.D.; Rodriguez, S.; Ferreira-Dias, S.; Bautista, F.; Romero, A.A. A comprehensive study of reaction parameters in the enzymatic production of novel biofuels integrating glycerol into their composition. Bioresour. Technol. 2010, 101, 6657-6662. [CrossRef] [PubMed]

30. Tan, K.T.; Lee, K.T.; Mohamed, A.R. A glycerol-free process to produce biodiesel by supercritical methyl acetate technology: An optimization study via response surface methodology. Bioresour. Technol. 2010, 101, 965-969. [CrossRef] [PubMed]

(C) 2019 by the authors. Licensee MDPI, Basel, Switzerland. This article is an open access article distributed under the terms and conditions of the Creative Commons Attribution (CC BY) license (http://creativecommons.org/licenses/by/4.0/). 